\title{
Macroscopic parameters of kidney and its clinical importance
}

\author{
T Prasuna ${ }^{1}$, Ashalatha Kasukurthy ${ }^{2 *}$, Teresa Rani $\mathrm{S}^{3}$
}

\author{
${ }^{1}$ Assistant Professor, Department of Anatomy, Kakatiya M edical College, Warangal, Telangana, INDIA. \\ ${ }^{2}$ AssociateProfessor, Department of Anatomy, RVM Institute of Medical Sciences and Research centre, Laxmakkapalli(V), Mulugu \\ (M),Siddipet (DT), Telengana - 502279 INDIA. \\ ${ }^{3}$ Associate Professor, Department of Anatomy, Guntur M edical College, Guntur, Andhra Pradesh, INDIA.
}

Email: drashasekhar@gmail.com

\begin{abstract}
Introduction: Fetal kidney length has been studied and shown strongly to correlate with the gestational age in late trimester even in IUGR fetuses. Establishment of gestational age is crucial for obstetricians to plan further treatment of the antenatal patient. Estimation of gestational age of fetus is of great medicolegal Importance. Objectives: The aim of the study was to determine the morphometric development of renal parameters like length, width, and circumference during the fetal period. Material and Methods: The present study was conducted in the Department of Anatomy Kakatiya Medical College, Warangal, having sample size of 100. Foetuses utilized for the study are of gestation period ranging from 20 weeks to 40 weeks. Kidney length, width, and circumference were measured and recorded. Result: A significant and strong positive correlation was found between the crown rump length and gestational age with renal dimensions including length, width and circumference. Conclusion: Growth of kidney was seen to be proportional to gestational age and crown rump length. This will also contribute to imaging of fetal kidneys and detection of kidney abnormalities in intrauterine period and early interventions.
\end{abstract}

Key Words: Gestational age, Biperietal diameter, Correlation, Fetal kidney length.

\section{*Address for Correspondence:}

Dr. Ashalatha Kasukurthy, Associate Professor, Department of Anatomy, RVM Institute of Medical Sciences and Research centre, Laxmakkapalli(V), Mulugu (M),Siddipet (DT), Telengana - 502279 INDIA.

Email: drashasekhar@gmail.com

Received Date: 04/01/2018 Revised Date: 30/01/2018 Accepted Date: 12/02/2018

DOI: https://doi.org/10.26611/1001521

\begin{tabular}{|l|l|}
\hline \multicolumn{2}{|c|}{ Access this article online } \\
\hline Quick Response Code: & Website: \\
\hline & www.medpulse.in \\
\cline { 3 - 3 } & \\
\hline
\end{tabular}

\section{INTRODUCTION}

Human kidney passes through three stages of evolution, pronephros, mesonephros and metanephros, during which kidney obtains its morphological and functional maturity. The fetal kidneys growth can be evaluated throughout pregnancy by measuring renal length and comparing it to normal charts. (As a simple rule, renal growth is $1.1 \mathrm{~mm} /$ gestational week) ${ }^{3}$. Fetal kidney length has been studied and shown strongly to correlate with the gestational age in late trimesters even in IUGR fetuses ${ }^{1}$.Establishment of gestational age is crucial for obstetricians to plan further treatment of the antenatal patient. Estimation of gestational age of fetus is of great medico legal Importance. ${ }^{2}$ An accurate estimation of gestational age is fundamental in order to better management of pregnancy, especially high-risk pregnancy ${ }^{4}$. The aim of this study was to determine the normal dimension of fetal kidney, including length and width and circumference at different gestational ages i.e., from 20 weeks to 40 weeks.

\section{MATERIAL AND METHODS}

The material used for present study are100 foetuses, which have been randomly collected from Government Maternity Hospital, Hanumakonda and Chandra Kantha Memorial Hospital, Warangal in Warangal District of Telangana State. Foetuses utilized for the study are of gestation period ranging from 20 weeks to full term. They were still born or aborted spontaneously as mothers were of low socio-economic states with minimum antenatal 
care. The foetuses once certified dead were preserved by injecting $20 \mathrm{cc}$ to $100 \mathrm{cc}$ of $10 \%$ formalin into abdomen, thorax and cranial cavity through orbits. All the foetuses were immersed in a container filled with tank solution. The measurements were done by using compass, scale and verniercaliper, digital weight machine.

\section{OBSERVATION AND RESULTS}

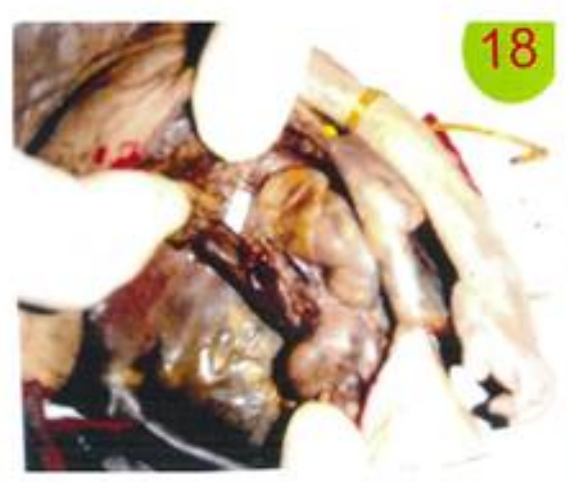

fig 1: 32 weeks female foetus

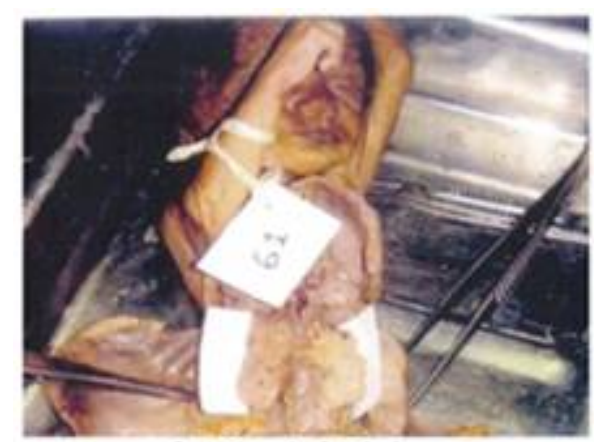

fig 4:32 weeks female fortas

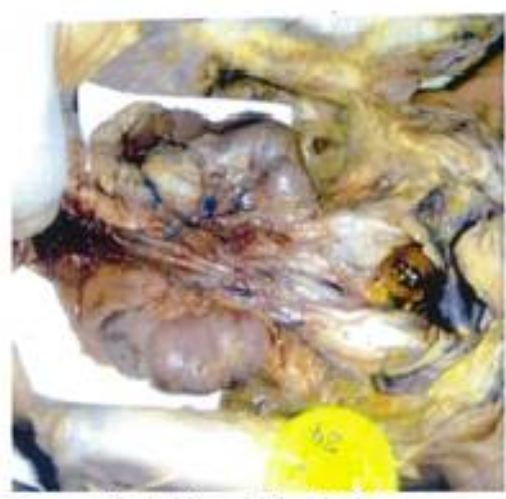

fig 2: 28 weeks female foetus

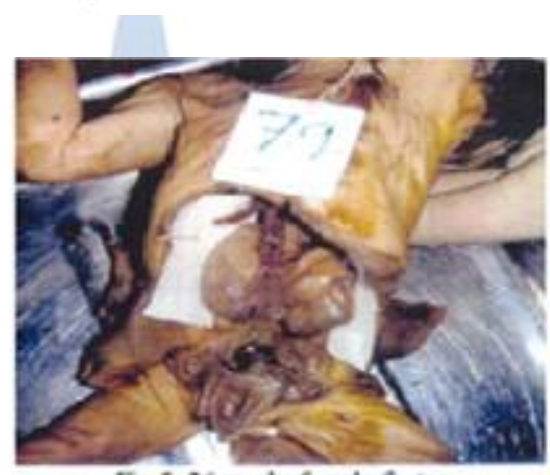

Fig 5: 36 weelo fomale foetue

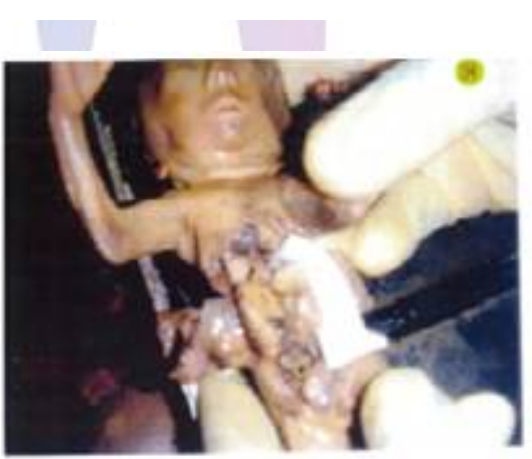

Fig 7.14 wreks male foetus

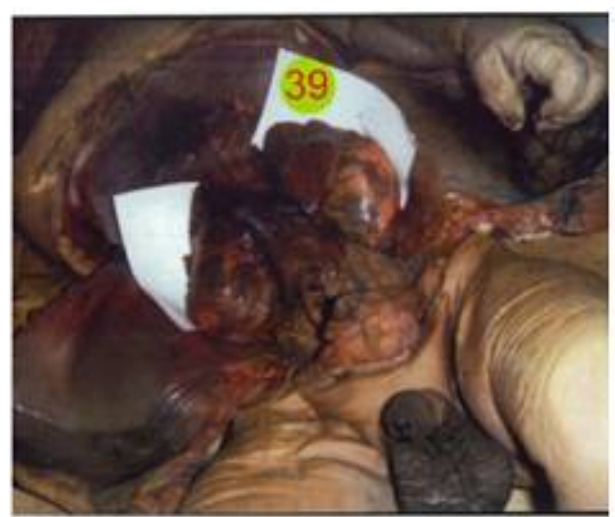

fig 3: 40 weeks male foetus

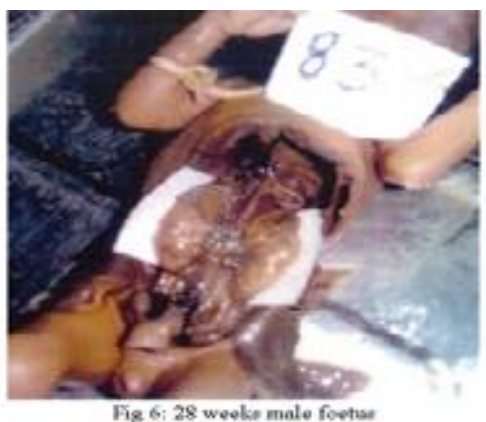

Fis 6: 28 weeke male foetse

Legend

Figure 1: 32 weeks female foetus; Figure 2: 28 weeks female foetus; Figure 3: 40 weeks male foetus; Figure 4: 32 weeks female foetus; Figure 5: 36 weeks female foetus; Figure 6: 28 weeks male foetus; Figure 7: 34 weeks male foetus

The mean foetal kidney length has increased from 21.0 $\mathrm{mm}$ at 20 weeks of gestation to $40.5 \mathrm{~mm}$ at 40 weeks of gestation (Table 3 ). There was statistically no significant variation between the measurement of the left and right foetal kidneys. Changes in foetal kidney width and foetal kidney circumference with gestational age are as shown in Table 3. Foetal kidney width shows a linear increase by 1.4 to $1.9 \mathrm{~mm}$ every 2 weekly as is evident in this Table 3 .
Foetal kidney circumference shows a linear increase by 1.1 to $2.5 \mathrm{~mm}$ every 2 weeks. Figure 3 a,b,c shows linear graphs of the foetal kidney length, foetal kidney width and foetal kidney circumference in the study against the gestational age. Foetal kidney width shows a linear increase by 1 to $1.5 \mathrm{~cm}$ and every 2 weeks. Foetal kidney circumference shows a linear increase by 1.5 to $1.9 \mathrm{~mm}$ every 2 weeks. 
Table 1: Measurements of fetal bi parietal diameter, fetal length, and fetal weight

\begin{tabular}{ccccc}
\hline $\begin{array}{c}\text { GA } \\
\text { (Weeks) }\end{array}$ & N & BPD(mm) & $\begin{array}{c}\text { Fetal length } \\
\text { (cm) }\end{array}$ & $\begin{array}{c}\text { Fetal weight } \\
\text { (gms) }\end{array}$ \\
\hline 20 & 4 & 48 & 25.4 & 300 \\
22 & 1 & 54 & 27.6 & 430 \\
24 & 19 & 58 & 30 & 600 \\
26 & 5 & 65 & 35.6 & 760 \\
28 & 17 & 70 & 37.6 & 1000 \\
30 & 6 & 75 & 39.9 & 1300 \\
32 & 15 & 80 & 42.4 & 1700 \\
34 & 12 & 84 & 45 & 2100 \\
36 & 11 & 88 & 47.4 & 2600 \\
38 & 8 & 93 & 49.8 & 3000 \\
40 & 2 & 96 & 51.2 & 3500 \\
\hline
\end{tabular}

Table 2: Relationship of kidney length, width, and circumference with gestational age and crown rump length

\begin{tabular}{ccccc}
\hline Kidney parameters & \multicolumn{2}{c}{ Crown rump length } & \multicolumn{2}{c}{ Gestational age } \\
& R & P value & R & P value \\
\hline Length & 0.99 & $\varangle .00001$ & 0.99 & $\varangle 0.00001$ \\
Width & 0.97 & $\varangle .00001$ & 0.99 & $\varangle 0.00001$ \\
Circumference & 0.99 & $\varangle .00001$ & 0.98 & $\varangle 0.00001$ \\
\hline
\end{tabular}

Table 3: M easurements of fetal kidney length, width, circumference and gestational age

\begin{tabular}{ccccc}
\hline $\mathrm{GA}^{1}($ Week $)$ & $\mathrm{N}^{2}$ & $\mathrm{FKL}^{3}(\mathrm{~mm})$ & $\mathrm{FKW}^{4}(\mathrm{~mm})$ & $\mathrm{FKC}^{5}(\mathrm{~mm})$ \\
\hline 20 & 4 & 21 & 13.5 & 39.5 \\
22 & 1 & 21.91 & 14.9 & 40.51 \\
24 & 19 & 23.5 & 15.85 & 42 \\
26 & 5 & 25.5 & 16 & 45.2 \\
28 & 17 & 29.5 & 17.5 & 50.1 \\
30 & 6 & 30.3 & 18.5 & 52.2 \\
32 & 15 & 32.5 & 19.75 & 54.1 \\
34 & 12 & 33.5 & 21 & 56.5 \\
36 & 11 & 36.15 & 22.92 & 58 \\
38 & 8 & 38.15 & 23.5 & 60.1 \\
40 & 2 & 40.5 & 24.65 & 62.5 \\
\hline
\end{tabular}

$1=$ gestational age, $2=$ number, $3=$ fetal kidney length,4fetal kidney width, $5=$ fetal kidney circumference.

Table 4: Relationship of fetal biparietal diameter, fetal length and weight with gestational age

\begin{tabular}{ccc} 
& \multicolumn{2}{c}{ Gestational Age } \\
& R & P value \\
\hline BPD & 0.99 & $\varangle 0.00001$ \\
Fetal length & 0.99 & $\varangle .00001$ \\
Fetal weight & 0.98 & $\varangle .00001$ \\
\hline
\end{tabular}

A significant and strong positive correlation were found between the crown rump length and gestational age with renal dimensions including length, width and circumference. The correlation between gestational age, Crown rump length and mean fetal kidney length is highly significant with pearson's correlation coefficient value of $0.99,0.99$ respectively and significance being $<0.00001$. The correlation between gestational age, Crown rump length and mean fetal kidney width is highly significant with pearson's correlation coefficient value of $0.99,0.97$ respectively and significance being $<0.00001$. The correlation between gestational age, Crown rump length and mean fetal kidney circumference is highly significant with pearson's correlation coefficient value of $0.98,0.99$ respectively and significance being $<0.00001$. A significant and strong positive correlation was found between gestational age with BPD, fetal length and fetal weight. The correlation between gestational age and BPD is highly significant with pearson's correlation coefficient value of 0.99 and significance being $<0.00001$. The correlation between gestational age and fetal length is highly significant with pearson's correlation coefficient value of 0.99 and significance being $<0.00001$. The correlation between gestational age and fetal weight is highly significant with pearson's correlation coefficient value of 0.98 and significance being $<0.00001$.

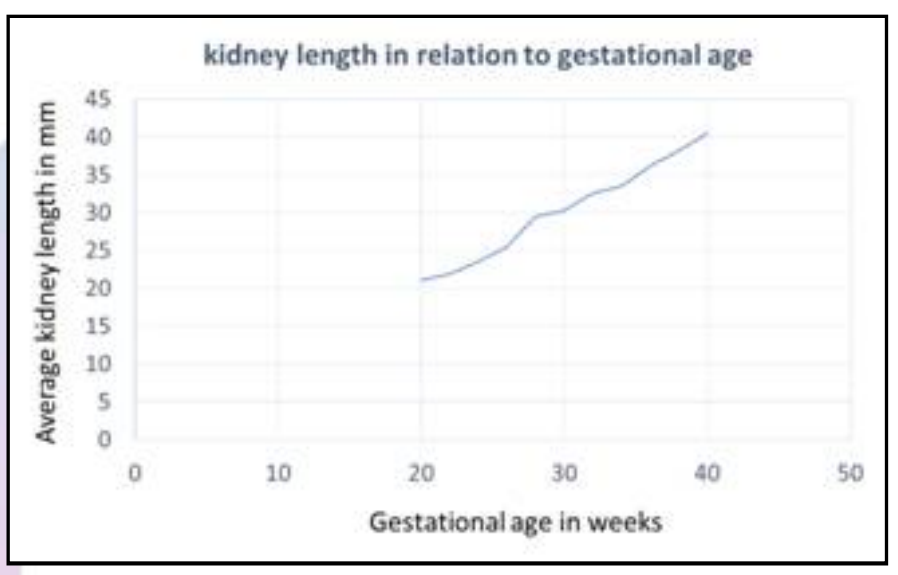

Figure 1:

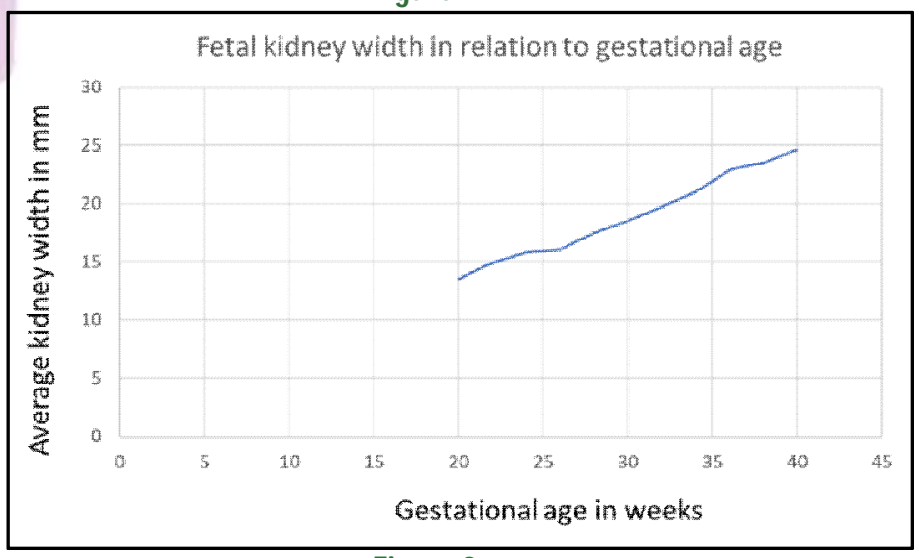

Figure 2: 


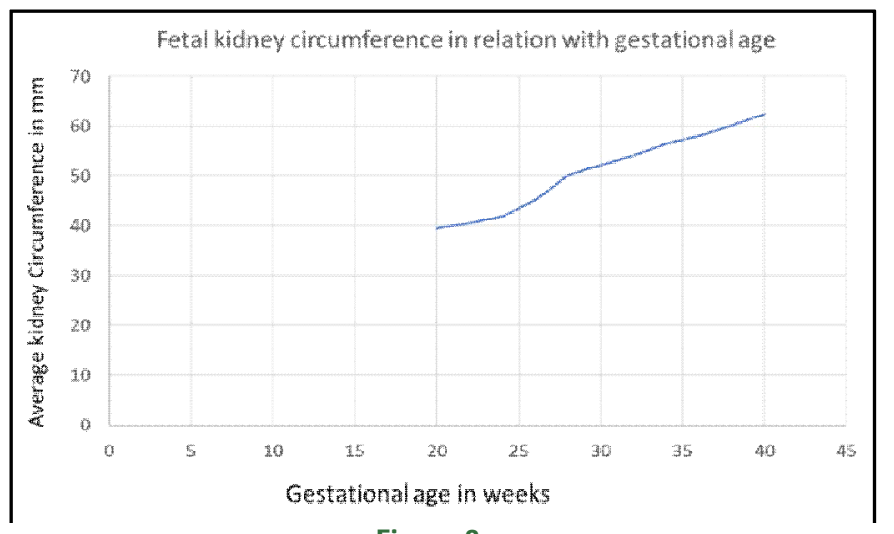

Figure 3:

\section{DISCUSSION}

Fetal kidney has been shown a steady growth of $1.7 \mathrm{~mm}$ fortnightly throughout pregnancy and is unaffected by growth abnormalities ${ }^{5}$. The previous studies have shown that fetal kidney length, width, and circumference are directly proportional to the Gestational age. Hence this study was undertaken to evaluate the various kidney dimensions in fetus. No significant difference was found between right and left renal lengths in fetuses. As the differences between measurements of the left and the right kidney are minimal ${ }^{6,7}$, measurement of one side kidney is considered sufficient. Sex of the fetus did not alter the measurements of the fetal kidney ${ }^{8}$. Thus, in the present study mean of kidney length is taken for study without consideration to fetal sex. It is also evident from this study that as the gestational age increases, the length of fetal kidney also increases and there is significant difference in the mean fetal kidney length that is found when lengths are compared across the 22 to 39 weeks of gestational age $(0<0.001)^{1}$. Mean length of the kidney increases with gestational age 9 . The study of Lawson et al using articulated arm scanning, showed measurement of $32 \mathrm{~mm}$ at 30 weeks and measurement of $42-43 \mathrm{~mm}$ at term, which are closer to our Measurements ${ }^{10}$. Ansari et al also in their sonographic study of 793 fetus for measurement of normal fetal kidney length in Bangladesh reported that the average fetal kidney length of full term is $39.5 \mathrm{~mm}$. The findings are closer to our study ${ }^{11}$. Foetal kidney size increases with gestational age. Fetal Kidney parameters are most accurate for estimating gestational age than other biometric indices. Accurate gestational age estimation is very important to an obstetrician for diagnosis of growth disorders, in assessment of wrong dates or forgotten dates and timing of delivery either by induction or caesarean section ${ }^{12}$.

\section{CONCLUSIONS}

Fetal kidney length shows a strong correlation with fetal gestational age. This is useful in detection of kidney abnormalities in intrauterine period and early interventions.

\section{REFERENCES}

1. Chatterjee $\mathrm{S}$ et al. Int $\mathrm{J}$ Reprod Contracept Obstet Gynecol. 2016 Jun; 5(6):1949-1952.

2. Castellana C., Kosa F. Morphology of the cervical vertebrae in the fetal-neonatal human skeleton. Journal of anatomy 1999; 194: 147-152.

3. Filly P.A.,Feldstein V.A. Ultrasound Evaluation of normal fetal anatomy. In: Callen PW, editor. Ultrasonography in obstetrics and gynecology. 5th ed. Philadelphia: Saunders; 2007. p. 342-3.

4. Yusuf N, Moslem F, Haque J A. Fetal Kidney Length: Can be a New Parameter for Determination of Gestational Age in 3rd Trimester. TAJ: Journal of Teachers Association. 2007; 20(2).

5. Kansaria JJ, Parulekar SV. Nomogram for fetal kidney length. Bombay Hosp J. 2009; 51(2):155-62.

6. Konje JC, Okaro CI, Bell SC, DeChazal R, Taylor DJ. Evaluation of the accuracy and reliability of the use of fetal kidney length measurement in the determination of the gestational age after the $24^{\text {th }}$ week of pregnancy. Ultrasound Obstet Gynecol. 1998.

7. Cohen HL, Cooper J, Eisenberg P, Mandel FS, Gross BR, Goldman MA, et al. Normal length of fetal kidneys: sonographic study in 397 obstetric patients. AJR Am J Roentgenol. 1991; 157(3):545-8.

8. Konje JC, Abrams KR, S. C. Bell, D. J. Taylor.Determination of gestational age after 24th week of gestation from fetal kidney length measurement. Ultrasound Obstet Gynecol. 2002; 19:592-7.

9. Bertagnoli L, Lalatta F, Gallicchio R. Quantitative characterized the growth of the fetal kidney. JCU.1983; 11:349-56.

10. Lawson T, Filey W, Berland L, Clark K. Ultrasonic Evaluation of lens kidneys : analysis of normal size and frequency of visualization as relevant to stage of pregnancy. Radiology. 1981; 138:153-6.

11. Ansari SM, Saha M, Paul AK, Mia SR, Sohel A, Karim R. Ultrasonic study of 793 foetuses. Measurement of normal fetal kidney length in Bangladesh. Australias Radiol. 1997; 41(1):3-5.

12. Kaul I,MeniaV,AnandAK,Gupta R. Role of Fetal Kidney Length in Estimation of Gestational Age. JK science 2012 April - June; 14(2):65-9.

$$
\begin{aligned}
& \text { Source of Support: None Declared } \\
& \text { Conflict of Interest: None Declared }
\end{aligned}
$$

